\title{
Determining suspended solids and total phosphorus from turbidity: comparison of high-frequency sampling with conventional monitoring methods
}

\author{
Ana Villa $[$ • Jens Fölster • Katarina Kyllmar
}

Received: 13 June 2018 / Accepted: 27 August 2019 / Published online: 4 September 2019

(C) The Author(s) 2019

\begin{abstract}
Suspended solids (SS) are important carriers of pollutants such as phosphorus $(\mathrm{P})$ in streams, but the sampling frequency in monitoring programs is usually insufficiently frequent to capture episodic SS and total P (TP) peaks. The suitability of turbidity and conductivity as a surrogate for SS and TP was studied using 108 monitoring stations located in catchments of different sizes, land uses, and pollution levels. The use of highfrequency turbidity measurements to estimate SS and TP loads was compared with the use of two sampling methods (grab, flow-proportional sampling) in a case study. When all samples were considered, turbidity was a good predictor of SS $\left(r^{2}=0.76\right)$ and TP $\left(r^{2}=0.75\right)$. For single sites, there was a large range in how well turbidity could predict the two variables. The sitespecific turbidity-SS relationship was significant at $87 \%$ of sites (mean $r^{2}=0.72$ ). The site turbidity and conductivity-TP relationship was significant at $78 \%$ of sites (mean $r^{2}=0.62$ ). A stronger turbidity-SS
\end{abstract}

\footnotetext{
A. Villa $(\bowtie) \cdot$ K. Kyllmar

Department of Soil and Environment, Swedish University of Agricultural Sciences, P.O. Box 7014, 75007 Uppsala, Sweden e-mail: ana.villa@slu.se
}

\author{
K. Kyllmar \\ e-mail: katarina.kyllmar@slu.se \\ J. Fölster \\ Department of Aquatic Sciences and Assessment, Swedish \\ University of Agricultural Sciences, P.O. Box 7050, \\ 75007 Uppsala, Sweden \\ e-mail: jens.folster@slu.se
}

relationship was found in catchments with a higher percentage of agricultural land. The turbidity and conductivity-TP relationship was stronger when the TP concentration was high. In the case study, TP loads were smallest when estimated with grab sampling, which missed several discharge peaks. Loads estimated with high-frequency turbidity measurements were $19-51 \%$ smaller than with flow-proportional sampling, probably due to differences in sampling points. High-frequency turbidity measurements can be a viable alternative to conventional sampling methods in studies on concentration dynamics and load estimates.

Keywords Turbidity · Suspended solids · Highfrequency sensor $\cdot$ Phosphorus transport

\section{Introduction}

Eutrophication caused by excessive nutrient concentrations and loads in surface waters is affecting the Baltic Sea (Karlson et al. 2002) and many other water bodies around the world (Smith 2003). In response to this growing problem, measures aiming at restoring affected water bodies and controlling nutrient transport have been introduced (Sharpley et al. 2000; Hart 2003; Schutz et al. 2017). To evaluate the effectiveness of mitigation measures, proper monitoring of surface waters is needed to classify water status accurately, detect trends over time, and estimate pollutant loads discharging into water bodies. These objectives are specified in European Union legislation, e.g., the Water 
Framework Directive (WFD) (2000/60/EC), and political bodies, e.g., the Commission for the Protection of the Marine Environment in the Baltic Sea Area (HELCOM 2013).

Given the variation in water quality in space and time, the representativeness of samples is a critical issue when selecting the most appropriate monitoring strategy and frequency. To date, the most common monitoring frequency has been monthly or fortnightly grab sampling (Ferreira et al. 2007). This can be sufficient for some indicators, contaminants, or purposes, but not others, since, e.g., Skeffington et al. (2015) showed that, using monthly sampling, a particular water body could be described as having good, moderate, or poor ecological status due to random sampling effects. "Good Ecological Status" is the WFD default objective for all water bodies and is defined as only slight variation from undisturbed conditions. Monthly or fortnightly grab sampling often misses short highconcentration peaks in suspended solids (SS) and total phosphorus (TP) (Brauer et al. 2009), which typically originate from small areas of a catchment (Sharpley et al. 2009) and occur during a few high-flow episodes per year (Bowes et al. 2003; Horowitz 2008). Decreasing sampling frequency increases the variability and uncertainty in annual load estimates (Bowes et al. 2009; Bieroza et al. 2018). Cassidy and Jordan (2011) found that only nearcontinuous monitoring (e.g., hourly and sub-hourly sampling) is able to capture the large temporal changes in TP concentrations in small agricultural streams. More frequent measurements of SS or TP concentrations than those used in conventional monitoring are needed to reduce the uncertainty in long-term load estimates, especially in flashy streams (Jones et al. 2012) and in streams with large losses of SS and TP. Composite sampling, such as flowproportional sampling, is another strategy used to improve load estimates and have been explored and integrated in agricultural monitoring catchments in the Nordic and Baltic countries (Kyllmar et al. 2014a). Cassidy et al. (2018) showed that load estimates based on flow-proportional composite sampling were accurate when compared against estimates from daily and sub-daily discrete sampling. However, while flow-proportional sampling improves the accuracy of load estimates, it does not describe temporal or spatial variations in water quality. In practice, an increase in frequency to weekly or daily sampling is not always possible, due to high costs and resource constraints. In the selection of a sampling strategy, costs and accuracy need to be balanced when seeking to obtain a proper representation of concentrations and loads (Brauer et al. 2009).
High-frequency measurement with sensors is an increasingly common sampling option (Rode et al. 2016). It is seen as more cost-effective, allowing a greater number of measurements to be made compared with conventional grab sampling regimes (Davies-Colley and Smith 2001). Collection of high-frequency data at multiple sites has been proven to quantify effectively the spatial and temporal variation in water quality constituent fluxes (Horsburgh et al. 2010). However, constituents such as SS and P cannot be measured with current in situ sensors and surrogate measures to estimate them are needed. Turbidity has been widely used as a surrogate to predict concentrations of suspended particles (Bilotta and Brazier 2008). It is a relative measure of light diffraction in water caused by suspended particles. The use of turbidity as a surrogate for TP is based on the premise that most of the TP transported in streams is in particulate form (Settle et al. 2007; Stubblefield et al. 2007; Ruegner et al. 2013). While the relationship between turbidity and SS may be confounded by factors such as variations in particle size distribution, particle composition, or water color (Ruzycki et al. 2014; Bright et al. 2018), a certain level of error can be tolerated, as continuous estimation of SS concentrations overcomes the greatest error, which derives from infrequent sampling (Gippel 1995). High-frequency sensor surrogate measurements can be expected to reduce the uncertainty in load estimation by accounting for variations in concentrations and can produce similar results for SS and TP as continuous sampling (e.g., hourly, daily), which can be considered to represent the true loads. Conductivity is another surrogate parameter that has been widely used, as it is easy and inexpensive to measure. Continuous conductivity measurements have served for hydrograph separation (Heppell and Chapman 2006; Pellerin et al. 2008; Lange and Haensler 2012) and could potential complement turbidity as a surrogate of TP concentration measurements when there are sources of $\mathrm{P}$ of different hydrological origins.

Most previous studies involving the use of surrogates to estimate SS and TP concentrations have focused on a few heavily monitored sites, while only a few studies have used multiple sites. Recently, Schilling et al. (2017) evaluated 43 different river monitoring sites in Iowa and found that TP concentrations were highly correlated to turbidity, with a mean correlation coefficient ( $r$ ) of 0.78. Davies-Colley et al. (2014) used 77 diverse New Zealand rivers to explore the relationships between SS, turbidity, and visual clarity and found that 
SS and turbidity were highly correlated $\left(r^{2}=0.87\right)$ when all samples from the 77 sites for a 12-month period were pooled. The standard error (SE) was also high (0.313) in that study, meaning that the relationship was not precisely predictive, possibly due to the large variation between individual sites. For individual sites, they found lower SE values, suggesting that turbidity could be used as a surrogate for SS when site-specific relationships are established (Davies-Colley et al. 2014). Grayson et al. (1996) evaluated the use of general relationships with pooled data from sites throughout a $5000-\mathrm{km}^{2}$ catchment, under a wide range of flow conditions and were able to explain $70-90 \%$ of the variation in the relationships despite a wide range of flow, climate, and catchment conditions. Discharge-specific regressions are reported to show higher $r^{2}$ values than those based on pooled data (Pfannkuche and Schmidt 2003; Lacour et al. 2009). However, the general relationships in those studies still showed $r^{2}$ values above 0.8. Stutter et al. (2017) found that the correlations between turbidity and TP or SS are always site-specific and thus nontransferable between catchments.

In the present study, we explored the use of surrogates (turbidity and conductivity) for SS and TP concentrations in an extensive dataset of 108 sites across Sweden. The sites ranged from first-order rivers (which cover the entire catchment to the estuary) to small headwater streams and catchments with various land uses (from pristine forest catchments to heavily polluted agricultural catchments). The use of high-frequency measurements of surrogate parameters is of particular interest in Sweden, where over $90 \%$ of the total length of perennial streams $(530,000 \mathrm{~km})$ is associated with a catchment area of less than $15 \mathrm{~km}^{2}$ (Bishop et al. 2008). Many headwater catchments are currently not being monitored, as doing so with the current sampling method (i.e., grab sampling) would not be feasible due to the large number of water bodies involved. The use of sensors to measure proxy parameters could help extend the number of monitored sites and improve estimation of SS and TP concentrations and loads, especially since lower-cost, robust sensors for long-term field deployment are becoming more readily available. However, before making use of proxy turbidity measurements, the relationship between turbidity and SS and TP needs to be determined in a number of streams.

The aims of this study were thus (1) to evaluate the use of turbidity as a surrogate for SS and TP concentrations at 108 river monitoring sites in Sweden, using general and site-specific relationships, and (2) to compare TP load estimates obtained using high-frequency sensor measurements, grab sampling, and flow-proportional sampling.

\section{Materials and methods}

Study areas and sampling strategy

The analysis was performed on a set of 108 stream monitoring stations included in national and regional monitoring programs, research projects, and the "coordinated recipient monitoring" program (Recipientkontroll ( $S K K$ och $R K$ ) in Swedish). The latter is the statutory monitoring program conducted by dischargers of pollutants (e.g., private companies, municipalities) downstream of the discharge site. The study sites were distributed across different regions in Sweden, from latitude $57^{\circ} \mathrm{N}$ to $64^{\circ} \mathrm{N}$, covering a wide range of catchment sizes, land uses, and pollution levels (Fig. 1). Catchment size ranged from 0.24 to $4182.4 \mathrm{~km}^{2}$ (median $110.3 \mathrm{~km}^{2}$ ), which included sites ranging from small tributary streams to first-order rivers. The most extensive land use in the catchments was forestry (median $72 \%$ ), followed by agriculture (median 9\%). The latter was mainly concentrated in southern Sweden (Fig. 1). Only three sites, in the region of Stockholm, were located in catchments with more than $25 \%$ urban land. Otherwise, the median urban area was around $2 \%$. Land use data on the catchments were extracted from the CORINE Land Cover datasets (European Commission 1993). The number of point sources upstream from the monitoring site was correlated to the size of the watershed area and varied from 0 to 24 . The density of the point sources ranged from zero- to 0.075 -point source per $\mathrm{km}^{2}$ catchment area (median 0.0035 ). There were 48 sites with no upstream point sources, while 17 sites had only one upstream point source. Data on the presence and number of point sources in the catchments were extracted from the Swedish pollution load compilation for the Baltic Sea (Swedish Environmental Protection Agency 2008).

The sites were sampled between 10 and 71 times each during the period 2010-2012, at a frequency ranging from every 2 weeks to every 4 months, and the samples were analyzed for SS, TP, turbidity, and electrical conductivity. All sites were sampled at least once each season of the year during the study period. Overall at all stations, more samples were taken during autumn (median of 5 times per station), while spring and summer were 
sampled a median of 3 times at each station. Winter was the least sampled season (median of 2 times per station).

In a case study, different techniques for estimating TP loads were compared using a stream draining an agricultural catchment (code name U8) within the national monitoring program for agricultural catchments (Kyllmar et al. 2014b). The catchment is located within the expanded area in Fig. 1 and covers approximately 6 $\mathrm{km}^{2}$, with $56 \%$ of the area dedicated to arable land. The long-term precipitation at the site is $539 \mathrm{~mm}$, and the mean annual temperature is $5.9^{\circ} \mathrm{C}$ (Kyllmar et al. 2014b). The dominant soil texture (according to the USDA classification) is clay. Water discharge in the stream was measured using a level gauge and a Vnotch weir located upstream. Flow was measured every $30 \mathrm{~s}$ and then stored as daily mean values. The stream was sampled with two parallel methods: fortnightly grab sampling and flow-proportional composite sampling. The flow-proportional composite sampling was performed at a point situated $50 \mathrm{~m}$ upstream from the grab sampling point. Land use in the catchment areas adjacent to these sampling points is similar, with no contribution from any extra point source. The fortnightly composite sample consisted of sub-samples of approximately $20 \mathrm{~mL}$, which were taken by a peristaltic pump every time a set volume of water passed the measurement station. The sub-samples were stored in a $10-\mathrm{L}$ glass bottle, and a water sample was taken from the bottle every 2 weeks and sent to the laboratory for analysis (Kyllmar et al. 2014b). Turbidity was measured every 10 min between 4 July and 3 December 2012, using a field sensor (Hach-Lange SOLITAX sc and a SC-1000 controller), at approximately $10 \mathrm{~m}$ downstream from the point of the flow-proportional water sampling. The measurement range of the instrument is 0.001-4000 formazin nephelometric units (FNU) (Hach 2009). The instrument had a self-cleaning wiper device that cleaned the sensor before each measurement.

The data used in this study from the monitoring stations and the case study are available in Villa et al. (2019).

\section{Laboratory analyses}

All analyses were performed with standard methods at the accredited laboratories of the Swedish University of Agricultural Sciences. Turbidity was measured using the standard method SS-EN ISO 7027 with the turbidimeter Hach 2100AN IS and expressed in FNU. Electrical conductivity was analyzed according to reference method SS-EN 27888-1 and expressed in $\mathrm{mS} \mathrm{m}^{-1}$. Concentration of suspended solids was determined gravimetrically after extraction by suction filtering through a $1.2-\mu \mathrm{m}$ glass fiber filter following a modified version of the standard method SS-EN 872:2005. The modification consists of analyzing the samples within 2 weeks instead of the standard $24 \mathrm{~h}$ and using a smaller pore size filter $(0.2-\mu \mathrm{m}$ membrane filter) in order to capture the small clay particles which dominate in the agricultural catchment. Total $\mathrm{P}$ was analyzed using the standard method SS-EN ISO 6878:2005, modified to adapt to the specific characteristics of the instrument Autoanalyzer 3 through the Bran*Luebbe Method No. G-175-96. Samples containing less than $4 \mu \mathrm{g}$ dissolved reactive $P$ (DRP) were analyzed following Bran*Luebbe Method No. G-175-96 Rev. 2 with a Bran*Luebbe Autoanalyzer 3. All other samples were pre-filtered (filter pore diameter $0.4 \mu \mathrm{m}$ ) to efficiently retain the colloidal clay particles and analyzed for DRP following the method ISO 15923-1:2013 using a Thermo Scientific ${ }^{\mathrm{TM}}$ Gallery ${ }^{\mathrm{TM}}$ Discrete Analyzer. Particulate phosphorus (PP) was determined as the difference between TP and DRP. Negative values of PP, ranging from -2 to $-1 \mu \mathrm{g} \mathrm{L}^{-1}$, were detected in $1 \%$ of samples (30 out of 2358). These were due to measurement uncertainty and were set to zero for data analysis.

Statistical analysis and calculations

The use of turbidity and conductivity as a surrogate for SS and TP was examined in the comprehensive study of the 108 monitoring sites through simple linear regression. The variables were log-transformed to fulfil the assumption of normal distribution of residuals. A non-parametric Spearman correlation test was used to assess whether a higher coefficient of determination $\left(r^{2}\right)$ in the turbidity-SS relationship was correlated with a percentage of agricultural land in a catchment. A non-parametric test was chosen because neither of the variables followed a normal distribution after log transformation. The impact of point sources on the relationship between turbidity/ conductivity and TP was studied through analysis of variance (ANOVA) by comparing groups either with or without any point sources in the catchments.

In the case study on the agricultural monitoring catchment, TP loads were calculated from the fortnightly grab samples, flow-proportional composite samples, and highfrequency sensor measurements of turbidity. Conductivity was not measured in the case study, due to breakdown of 
Fig. 1 Map showing the location of the sampling sites and land use over Sweden. Triangles represent sites located in catchments with $<$ $25 \%$ agricultural land, while circles are sites in catchments with $>25 \%$ agricultural land. The region with a higher density of samples is enlarged and includes a representation of streams

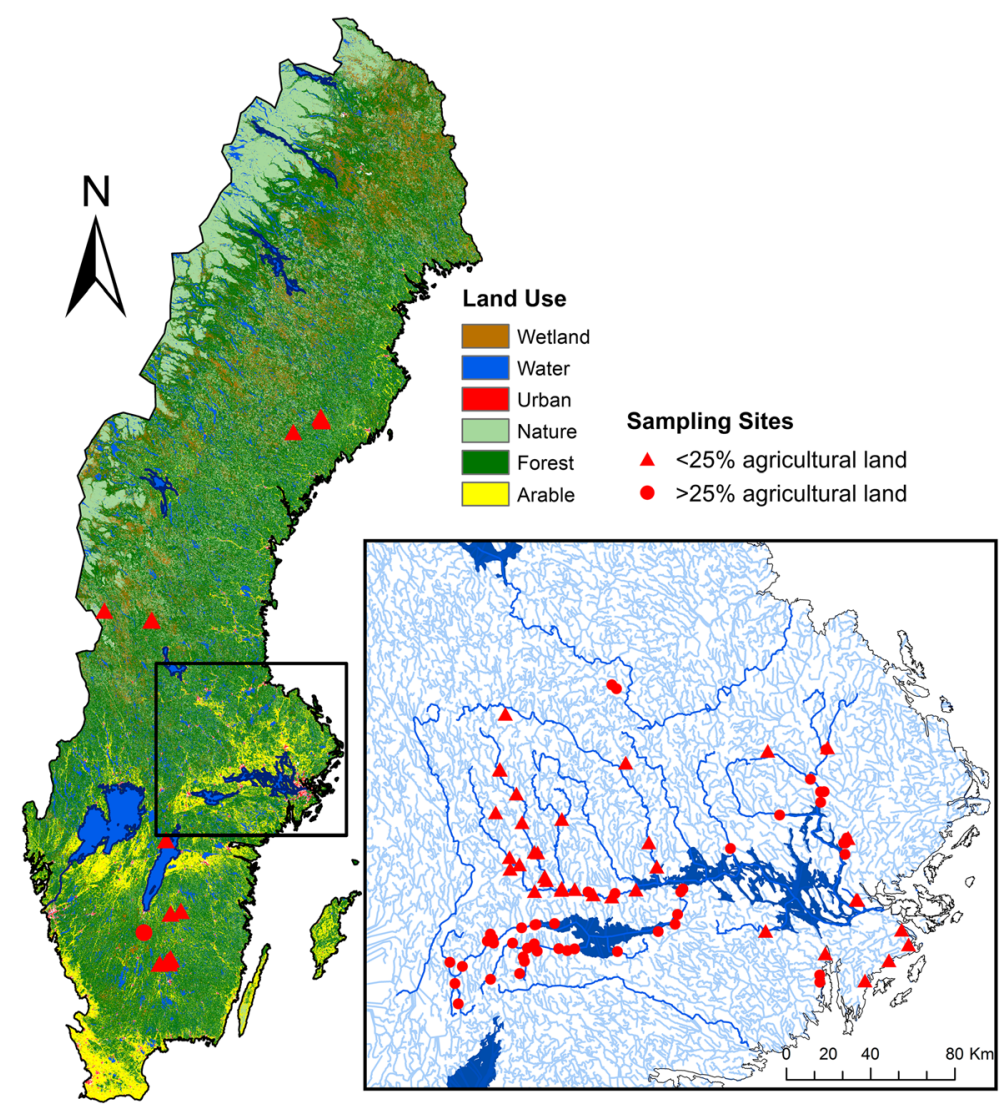

the sensor. For the fortnightly grab samples, TP loads were estimated using calculated daily concentrations, which were estimated by linear interpolation of the fortnightly samples. The calculated daily concentrations were then multiplied by the daily discharge recorded values (HELCOM 2015; OSPAR Commission 2014). For the composite samples, TP loads were obtained for 2-week periods by multiplying cumulative flow over the period by the actual concentration for that period. For the highfrequency sensor measurements, TP loads were estimated by first calculating TP concentrations from turbidity values using the regression equation established from the grab samples in the same stream. Daily transport was then calculated by multiplying the estimated daily mean TP concentration by the daily discharge. Uncertainty in the TP loads calculated from high-frequency turbidity measurements was estimated using the lower and upper $95 \%$ prediction intervals of the turbidity (from high-frequency measurements) to TP (from manual sampling) regression. Baseflow index was calculated as the ratio of the baseflow values to the total stream flow values (Gustard et al. 1992). The calculation was performed using the time series from
1994 to 2012. The index ranges from 0 to 1 and is used to describe the hydrology at the catchment. Catchments with baseflow index close to 1 have a higher contribution of groundwater to streamflow, while catchments with low baseflow index are characterized by a larger contribution of overland and near-surface lateral flow. The software JMP 14.0 from SAS was used for the statistical analysis and calculations.

\section{Results and discussion}

Turbidity, SS, and TP concentrations in streams

The range of turbidity, SS, and TP reflected the fact that the selected streams covered a variety of conditions, from clear pristine waters to more polluted waters (Table 1). Compared with long-term losses from Swedish monitoring agricultural catchments (Kyllmar et al. 2014b), the maximum value of SS and TP was above the 90th and 75th percentiles, respectively. 
Table 1 Concentrations of turbidity, suspended solids (SS), total phosphorus (TP), and conductivity measured at 108 stream monitoring sites in Sweden during 3 years (2010-2012)

\begin{tabular}{|c|c|c|c|c|c|c|c|}
\hline Variable & Sampling method & $N$ & Min. & Median & 75th percentile & 90th percentile & Max. \\
\hline \multirow[t]{2}{*}{ Turbidity (FNU) } & \multirow[t]{2}{*}{ Manual } & 2060 & 0.18 & 4.4 & 11.0 & 24.0 & 327.0 \\
\hline & & $1659^{\mathrm{a}}$ & 0.18 & 5.5 & 14.0 & 28.0 & 327.0 \\
\hline \multirow[t]{2}{*}{$\mathrm{SS}\left(\mathrm{mg} \mathrm{L}^{-1}\right)$} & \multirow[t]{2}{*}{ Manual } & 2060 & 1.00 & 6.8 & 13.7 & 21.9 & 309.3 \\
\hline & & $1658^{\mathrm{a}}$ & 1.00 & 5.4 & 11.4 & 21.5 & 309.3 \\
\hline \multirow[t]{2}{*}{$\mathrm{TP}\left(\mu \mathrm{g} \mathrm{L}^{-1}\right)$} & \multirow[t]{2}{*}{ Manual } & 2357 & 1.0 & 26.0 & 54.0 & 89.2 & 2222.0 \\
\hline & & $1955^{\mathrm{a}}$ & 1.0 & 31.0 & 62.0 & 95.4 & 2222.0 \\
\hline \multirow[t]{2}{*}{ Conductivity $\left(\mathrm{mS} \mathrm{m}^{-1}\right)$} & \multirow[t]{2}{*}{ Manual } & 2357 & 0.62 & 5.9 & 28.25 & 46.5 & 115.0 \\
\hline & & $1955^{\mathrm{a}}$ & 0.62 & 8.7 & 33.1 & 49.8 & 115.0 \\
\hline
\end{tabular}

${ }^{a}$ Excluding the clear-cut forested area of Balån (six sites)

Estimating SS from turbidity in streams

The general relationship between turbidity and SS considering all individual grab samples from all sites $(n=2061)$ produced an $r^{2}$ value of 0.53 (Fig. 2). When all the individual samples were plotted, two groups of samples were identified. One of the groups had a higher content of SS in relation to the turbidity value, meaning that the water samples had less ability to intercept light compared with other samples (Fig. 2). Most of these samples came from the clear-cut forested area of Balån, part of the Balsjö Catchment Study (Löfgren et al. 2009). The monitoring stations of Balån are those located farthest north in Fig. 1. When these samples were excluded from the analysis, $r^{2}$ increased to 0.76 (Table 2). For only the samples from Balån $(n=402)$, a lower $r^{2}$ was

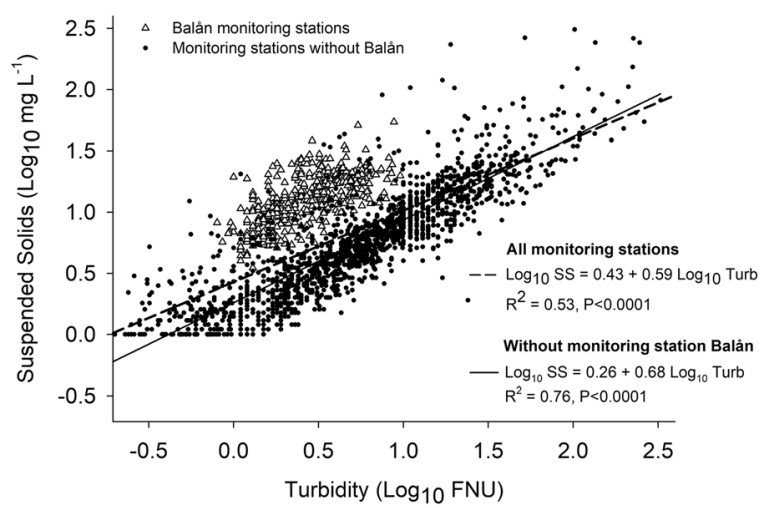

Fig. 2 Linear regression between suspended solids and turbidity for all individual measurements from the 108 monitoring stations ( $n=2061)$ and for samples excluding the samples from monitoring stations of Balån. Samples from the newly clear-cut forested area of Balån are represented by unfilled triangles obtained $\left(r^{2}=0.40, P<0.0001\right)$. Previous studies in this geographical area have reported an increase in dissolved organic carbon (DOC) concentrations in boreal streams after forest clear cutting (Schelker et al. 2014). Dissolved organic material causes water discoloration, which can reduce the recorded turbidity due to the light-absorbing dissolved substances (Gippel 1995; Bright et al. 2018). This could be a possible explanation for the deviating behavior of samples from the newly clear-cut forested area.

The calculated SS values obtained were compared against the measured values (Fig. 3, left). Greater deviations from the 1:1 line were observed with higher measured SS concentrations, which did not correspond to higher turbidity values. Underprediction of high values of measured SS has been observed by others (e.g., Minella et al. 2008) and could be related to the effect of aggregation caused by an increase in organic matter. Larger aggregated particles have low lightscattering capacity and hence produce lower turbidity values for a given SS concentration (Slaets et al. 2014). The high values of measured SS in our study were found in samples from different sites, different regions, and different months of the year. The majority of the other samples from such sites were close to the 1:1 line, and the deviations from the 1:1 line were exceptions. To improve the understanding of the turbidity-SS relationship, more samples with high SS values would be needed.

The site-specific relationship between turbidity and SS was significant $(P<0.05)$ for $87 \%$ of the sites (94 sites). Non-significant relationships resulted from sites located in predominantly forested catchments. In summary, the mean $r^{2}$ of all individual 
Table 2 Results from linear regression $(y=\alpha+\beta x)$ between suspended solids (SS) and turbidity and between total phosphorus (TP) and turbidity, for 3 years (2010-2012) at a range of 108 stream monitoring stations in Sweden

\begin{tabular}{|c|c|c|c|c|c|c|c|c|c|}
\hline $\begin{array}{l}\text { No. of } \\
\text { stations }\end{array}$ & $\begin{array}{l}\text { No. of } \\
\text { water } \\
\text { samples }\end{array}$ & $\begin{array}{l}\text { Linear } \\
\text { regression } \\
\text { term }(y)\end{array}$ & $x$ & $\alpha$ & $\beta$ & $r^{2}$ & RMSE & $95 \%$ CI $\beta$ & $95 \%$ CI $\alpha$ \\
\hline 108 & 2060 & Log SS & Log turbidity & 0.43 & 0.59 & 0.53 & 0.30 & $0.56-0.61$ & $0.41-0.45$ \\
\hline $102^{\mathrm{a}}$ & 1658 & Log SS & Log turbidity & 0.26 & 0.68 & 0.76 & 0.22 & $0.66-0.70$ & $0.24-0.27$ \\
\hline \multirow[t]{2}{*}{108} & 2356 & $\log \mathrm{TP}$ & Log turbidity & 1.09 & 0.60 & 0.75 & 0.22 & $0.59-0.62$ & $1.08-1.10$ \\
\hline & 2356 & $\log \mathrm{TP}$ & $\begin{array}{l}\text { Log turbidity, } \\
\text { log } \\
\text { conductivity }\end{array}$ & 0.98 & $\begin{array}{l}0.51 \text { (turbidity); } \\
0.17 \text { (conductiv- } \\
\text { ity) }\end{array}$ & 0.77 & 0.21 & $\begin{array}{l}0.49-0.52 \text { (turbidity); } \\
0.15-0.19 \text { (conductivi- } \\
\text { ty) }\end{array}$ & $0.97-1.00$ \\
\hline $102^{\mathrm{a}}$ & 1955 & $\log \mathrm{TP}$ & Log turbidity & 1.10 & 0.61 & 0.78 & 0.22 & $0.60-0.62$ & $1.10-1.11$ \\
\hline
\end{tabular}

All regressions were significant at $P<0.0001$

RMSE root mean square error, $C I$ confidence interval

${ }^{\mathrm{a}}$ Excluding the newly clear-cut forested area of Balån

significant regression equations was 0.72 (range 0.27-0.98), which was slightly lower than the value obtained for the general regression (0.76). The most common value was 0.78 , slightly above the mean. Mean slope for all the individual regressions was 0.8 (range 0.4-2.4). Coefficients $<0.5$ were found for 13 sites, and all but one of which were located in small headwater catchments. The dominant land use at these sites was forest, except for one site located in an urban catchment (> 50\% urban land use). Smaller streams have a faster response to precipitation and snowmelt and have higher variability in sediment response than larger rivers (Duvert et al. 2011; Jones et al. 2012). More frequent sampling could be needed in these small headwater forest streams to get a better description of SS variability and to confirm whether the use of turbidity is appropriate in this type of stream. Higher $r^{2}$ was moderately positively correlated with the percentage of agricultural land (Spearman $\rho=0.47, P<0.0001$ ) and weakly negatively correlated with the percentage of forest in the catchment (Spearman $\rho=-0.35, P<0.001$ ). Those catchments with $>27 \%$ of agricultural land all had coefficients $>0.6$, being the median value 0.85 (Fig. 4).

The number of observations made at each station and the $r^{2}$ values were weakly correlated (Spearman $\rho=-$ $0.24, P<0.05)$. In fact, for the 13 stations with only 10 observations, $r^{2}$ ranged from 0.1 to 0.95 . The median $r^{2}$ value for these stations was 0.74 , which was very close to the overall $r^{2}$ median value. The mean and median root mean square error (RMSE) for the site-specific regressions was 0.14 and 0.12 , respectively, i.e., lower than the RMSE found for the general relationship (0.22) (see Table 2 and

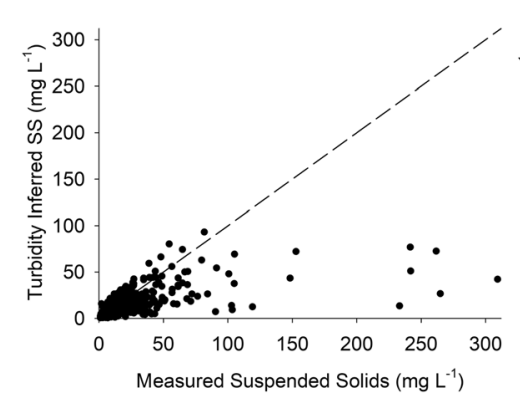

Fig. 3 (Left) turbidity-based (modeled) suspended solids (SS) compared with measured concentrations $\left(\mathrm{mg} \mathrm{L}^{-1}\right)$. (Right) turbidity-based (modeled) total phosphorus (TP) compared with measured concentrations $\left(\mu \mathrm{g} \mathrm{L}^{-1}\right)$. The dashed line in both graphs represents the 1:1 line. The regression equation used to calculate

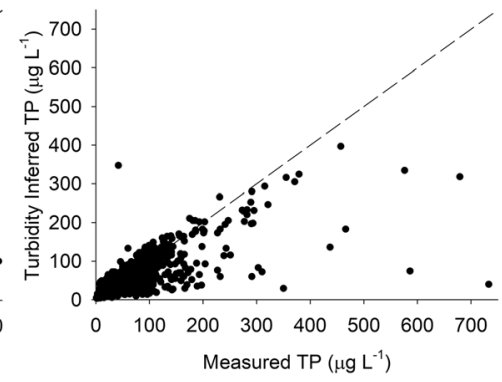

SS from turbidity values was as follows: $\log _{10} \mathrm{SS}=0.26+0.68$ $\log _{10}$ turbidity. The regression equation used to calculate TP from turbidity values was as follows: $\log _{10} \mathrm{TP}=1.09+0.60 \log _{10}$ turbidity 

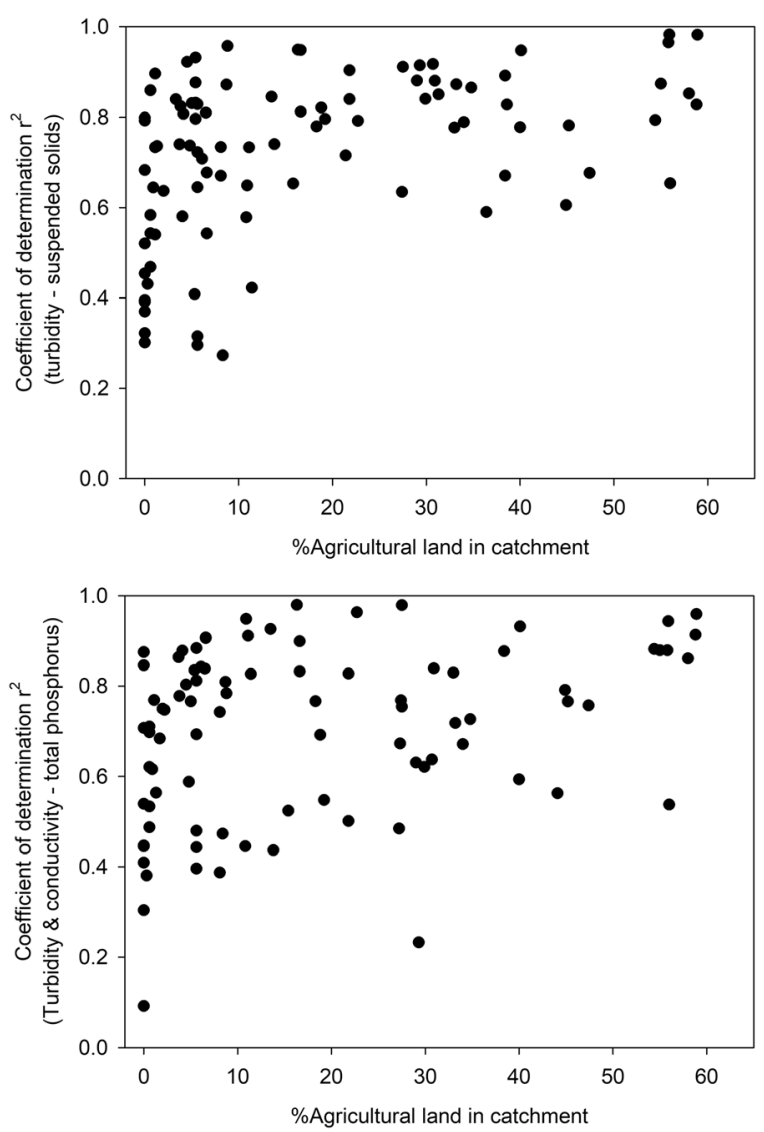

Fig. 4 Variation of the coefficient of determination $\left(r^{2}\right)$ with the \% agricultural land in the catchment, for the relationship between turbidity and suspended solids (SS) $(n=94$ sites out of 108) and between turbidity and conductivity and total phosphorus (TP) ( $n=$ 84 sites out of 108)

Fig. 5). These results indicate that most of the site-by-site regressions were more precisely predictive than the general relationship, which is in agreement with findings by Davies-Colley et al. (2014) for 77 rivers in New Zealand.

In summary, a general linear regression equation explaining the variation in SS with turbidity was applicable for most types of water bodies studied when streams draining clear-cut forested catchments at Balån were excluded. However, the error associated with predicting SS from turbidity for all the data was larger than that in more than $75 \%$ of the site-by-site regressions (Fig. 5). The range of the prediction error for single sites was also large. This implies that it is necessary to establish a site-specific relationship for any stream for which a turbidity sensor can potentially be used as a proxy for SS. Other studies have also shown that it is more appropriate to develop a specific regression for each stream and/or for dominant soil types (Grayson et al. 1996; Hayes et al. 2001), but this

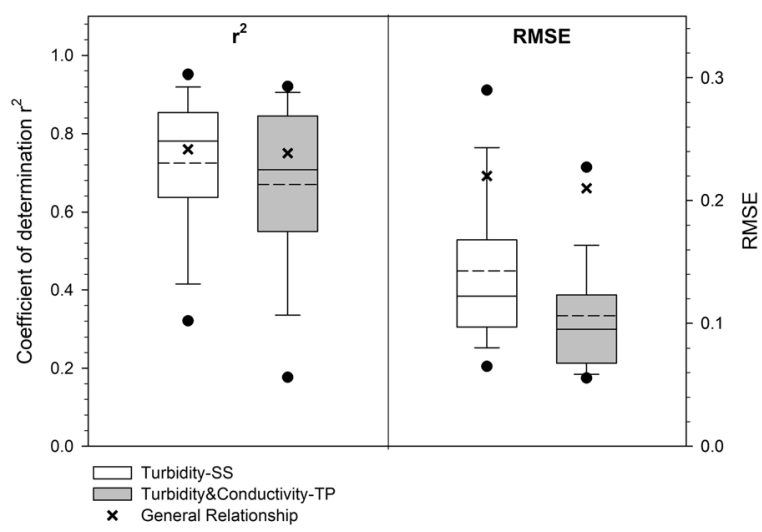

Fig. 5 Distribution of $r^{2}$ (left) and RMSE (right) values associated with the relationship between turbidity and suspended solids (SS) ( $n=94$ sites out of 108) and between turbidity and conductivity and total phosphorus (TP) $(n=84$ sites out of 108). Lower and upper boundaries of the box indicate the 25 th and 75 th percentiles, respectively. The dots represent the 5 th and 95 th percentiles. The line inside the box is the median, and the dashed line is the mean. Only significant relationships were considered. The crosses represent the values of the general relationships

is not always possible due to a lack of data and constraints on resources. In this sense, streams where a good relationship is known (e.g., catchments with a high percentage of agricultural land) should be selected first for the use of turbidity sensors. For instance, the use of turbidity in small forest streams may not be advisable, due to the low turbidity values found and/or to the variation in origin and quality of suspended matter, which leads to weak relationships.

As in many other studies (e.g., Gippel 1995; Ruzycki et al. 2014), we used linear regression to predict SS from turbidity. Other types of regression, including polynomial or power relations, have also been used to explain the variation in SS with turbidity, especially for higher turbidity values or changing sediment sources (e.g., Sun et al. 2001; Zabaleta et al. 2007). When establishing a sitespecific relationship, special efforts should be made to collect samples during high-turbidity events, to determine whether a linear or exponential model should be used. This was not possible in the present study, since we were restricted to the regular monitoring data.

Estimating TP from turbidity and conductivity in streams

The relationship between turbidity and TP determined from grab samples was studied through linear regression. When all individual observations were included, $r^{2}$ 
was $0.75(P<0.0001)$ (Table 2). Excluding the sites from the clear-cut forested area of Balån, $r^{2}$ only slightly increased to $0.78(P<0.0001)$.

The site-specific turbidity-TP relationship was significant for $78 \%$ of the sites (84 sites), with a mean $r^{2}$ value of 0.62 . When conductivity was introduced as a second explanatory variable, the mean $r^{2}$ increased to 0.67 (88 sites with significant regressions). At $25 \%$ of the sites, $r^{2}$ was higher than 0.84 (Fig. 5). At 79 stations (73\% of the total 108 stations), the turbidity-SS and turbidity-TP relationships were both significant. A greater variation in $r^{2}$ (range 0.10-0.94) was found for the turbidity-TP relationship than for the turbidity-SS relationship (Fig. 5). The large spread in $r^{2}$ values indicated that the sources and processes controlling the level of TP in different streams varied more than those controlling SS. Mean and median RMSE for the sitespecific regressions was 0.11 and 0.095 , respectively, i.e., lower than the RMSE found for the general relationship (0.21) (see Table 2 and Fig. 5). Over $90 \%$ of the site-specific regressions had a lower error than that obtained in the regression for the entire dataset (Fig. 5).

Higher $r^{2}$ was weakly positively correlated with the percentage of agricultural land (Spearman $\rho=0.34, P<$ 0.001 ) and weakly negatively correlated with the percentage of forest in the catchment (Spearman $\rho=-$ $0.33, P<0.001)$. Overall, higher $r^{2}$ values were found whenever there was a larger proportion of agricultural land in the catchment (Fig. 4), although this tendency is not as clear as in the case of the relationship turbiditySS. The presence (or not) of point sources in the catchments did not result in important differences in either the strength of the turbidity-TP relationship or the concentrations of TP. In catchments with no point sources, $r^{2}$ was significantly $(P<0.001)$ lower than that in catchments with point sources. The $r^{2}$ value from ANOVA between the two groups (i.e., presence of point sources and no presence of point sources) was low (0.1), indicating that the differences were not very important. The concentration of TP was significantly higher $(P<0.01)$ in catchments with point sources, but low $r^{2}(0.1)$ indicated that the difference could not be considered important. The relationship between turbidity and TP is reported to be influenced by the source of P (i.e., point or diffuse sources) (Viviano et al. 2014), by the flow conditions (Jordan et al. 2007), and probably most importantly, by the percentage of the different fractions of $\mathrm{P}$, with a stronger relationship obtained when PP is the dominant form (Jones et al. 2011). The dominant soil texture in a catchment also influences this relationship. For example, in clay-dominated catchments, the share of $\mathrm{P}$ from point sources is small due to high levels of background losses, which are predominantly in PP form.

In an effort to explain differences in $r^{2}$ values, we explored the reasons behind the distribution at different TP concentrations. Through visual inspection based on the distribution of $r^{2}$ values, two groups of $r^{2}$ for the mean TP concentrations at each site were distinguished (Fig. 6). At lower TP concentration values, $r^{2}$ values were evenly distributed $(0-1)$, but from around $50 \mu \mathrm{g}$ $\mathrm{L}^{-1}$, the distribution changed, with a larger proportion of $r^{2}$ values above 0.6 (Fig. 6). In the first group (TP $<$ $50 \mu \mathrm{g} \mathrm{L}^{-1}$ ), $r^{2}$ values were evenly distributed (from 0 to 0.95 ) and mean $r^{2}$ was 0.58 . In the second group (TP > $50 \mu \mathrm{g} \mathrm{L}^{-1}$ ), mean $r^{2}$ was slightly higher (0.62) and two main sub-groups, one with $r^{2}>0.6$ and another with $r^{2}<$ 0.4 , could be distinguished. In both groups ( 1 and 2$)$, low $r^{2}(<0.4)$ was mainly obtained for the non-significant relationships (Fig. 6). Overall, stronger relationships were found more consistently for high TP concentrations, which, in Sweden, often have a high particulate phosphorus content and are located in agricultural areas dominated by clay soils (Kyllmar et al. 2014b; Swedish Environmental Protection Agency 2009).

In summary, we did not detect correlations between $r^{2}$ values and average chemistry or catchment characteristics. Since there is a strong correlation between TP and clay

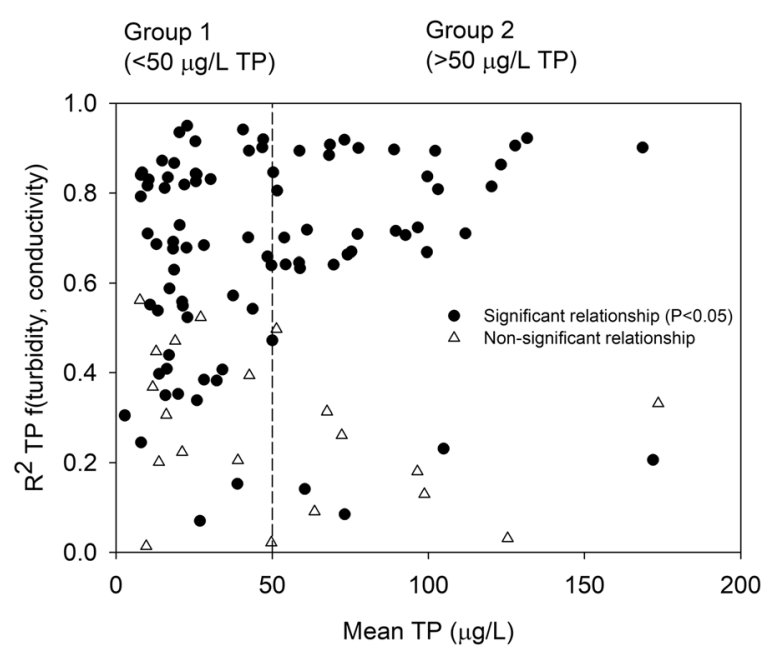

Fig. 6 Variation in $r^{2}$ (for the relationship between turbidity and total phosphorus (TP) and conductivity) with TP mean concentration at each site. Black dots represent significant relationships, while unfilled triangles represent non-significant relationships. The dotted line indicates a TP concentration of $50 \mu \mathrm{g} \mathrm{L}^{-1}$ 
content in the monitored agricultural catchments in Sweden (Kyllmar et al. 2014b), it is possible that data on soil type within the catchments would help predict where turbidity has the highest potential for use as a proxy for TP. Unfortunately, no data on soil texture was available for most of the catchments from the present study. A more detailed study of stream hydrology and the amounts exported by each of the point sources, together with the stream flow, could help explain the differing strength of relationships between turbidity and conductivity and TP. Based on our results, the turbidity and conductivity-TP relationship works better overall in agricultural catchments with high TP losses and when the proportion of PP is large, irrespective of the source. The use of turbidity as a proxy for TP in predominantly forested areas is less justifiable. Even when the proportion of PP was high, the relationship obtained was weak, indicating that the character of the particulate matter (e.g., mineral, organic) might have an influence on the relationship between turbidity and the amount of particles present. For instance, Gippel (1995) observed that organic particles give 2- to 3-fold higher turbidity readings than mineral particles at a given concentration and particle size. Even if a good relationship between turbidity as a proxy for SS and TP can be established, some regular monitoring by grab sampling will still be needed, especially if the aim of the monitoring is to follow the effect of mitigation measures. As Bechmann and Øgaard (2013) point out, the introduction of a mitigation measure leading to a reduction in TP losses (e.g., change in fertilization strategy) may not necessarily translate into a reduction in SS. For that reason, it is important to sample both SS and P, to correct and recalibrate their relationship with turbidity when needed.
Case study with in situ measurement of turbidity in an agricultural monitoring catchment

\section{Relationship between turbidity and SS, TP, and PP in grab samples}

Concentrations of SS from fortnightly grab sampling and high-frequency turbidity values for the same time point were significantly correlated $\left(r^{2}=0.87, P<\right.$ $0.0001)$. The use of mean daily turbidity values instead of selected specific time values coinciding with grab sampling gave very similar values and relationships. Concentrations of TP and PP from grab sampling were also significantly related by linear regression (Table 3) to the high-frequency daily mean turbidity measurements $\left(r^{2}=0.91, P<0.0001\right.$, for TP; $r^{2}=0.90, P<$ 0.0001 , for PP)

\section{In situ measurements compared with the analyzed water samples and modeled values}

The majority of sediments and particle-associated $\mathrm{P}$ are transported during storm events, so failing to capture high-flow peaks can lead to underestimation of SS and P loads (Jones et al. 2011). During the first half of the study period (July-September), flow was low, but during the second half (October-December), four large discharge episodes were recorded. These episodes coincided with peaks in turbidity (Fig. 7). Other turbidity peaks were recorded during the first half of the study period, at low flows, and could be attributed to small rain events during summer. Fortnightly grab sampling captured two of the high flow peaks but missed the other two. Mean and median concentrations of SS obtained

Table 3 Regression equations $(y=\alpha+\beta x)$ between turbidity and suspended solids (SS) and between turbidity and total phosphorus (TP) in the agricultural monitoring catchment U8 in the period 4 July-3 December 2012

\begin{tabular}{|c|c|c|c|c|c|c|c|c|}
\hline No. of observations & Linear regression term $(y)$ & $x$ & $\alpha$ & $\beta$ & $r^{2}$ & RMSE & $95 \%$ CI $\beta$ & $95 \%$ CI $\alpha$ \\
\hline 10 & Log SS (grab sample) & Log turbidity (time-specific) & 0.30 & 0.83 & 0.87 & 0.17 & $0.56-1.10$ & -0.19 to 0.79 \\
\hline 10 & Log SS (grab sample) & Log turbidity (daily mean) & 0.20 & 0.89 & 0.89 & 0.16 & $0.63-1.51$ & -0.28 to 0.67 \\
\hline 11 & Log TP (grab sample) & Log turbidity (time-specific) & -1.75 & 0.52 & 0.89 & 0.10 & $0.38-0.65$ & -1.99 to -1.51 \\
\hline \multirow[t]{2}{*}{11} & Log TP (grab sample) & Log turbidity (daily mean) & -1.81 & 0.55 & 0.91 & 0.09 & $0.42-0.68$ & -2.04 to -1.58 \\
\hline & Log PP (grab sample) & Log turbidity (time-specific) & -2.06 & 0.59 & 0.87 & 0.12 & $0.42-0.77$ & -2.37 to -1.75 \\
\hline 11 & Log PP (grab sample) & Log turbidity (daily mean) & -2.13 & 0.64 & 0.90 & 0.11 & $0.47-0.80$ & -2.41 to -1.84 \\
\hline
\end{tabular}

Concentrations of SS and TP were analyzed in the grab samples, and turbidity was measured by an in situ sensor. All regressions were significant at $P<0.0001$

$R M S E$ root mean square error, $C I$ confidence interval 
Fig. 7 Temporal variation in mean daily turbidity (black line) and mean daily discharge (gray line) at the outlet of the agricultural monitoring catchment U8 in the period 4 July-3 December 2012. Concentrations of total phosphorus (TP) are represented by dots (fortnightly grab sampling) and a cross (end of a 2week period of flow-proportional sampling). The modelled TP concentrations calculated from high-frequency turbidity measurements are represented by the dashed line

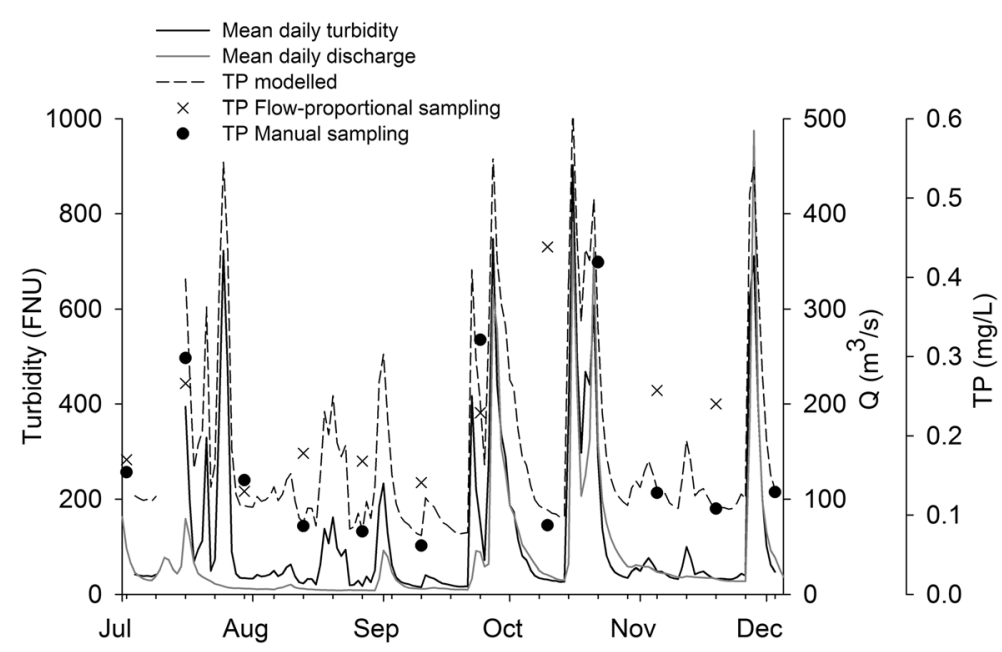

from fortnightly grab sampling and those estimated from turbidity were similar (Table 4). The main difference was observed in the higher ranges (both the 90th percentile and the maximum), which were higher in the case of turbidity-based SS. For TP, the pattern observed was very similar, with the greatest difference in the maximum values. PP ranged from 0.03 to $0.34 \mathrm{mg} \mathrm{L}^{-1}$ (Table 4). It was the main fraction of $P$ in 10 of the 11 samples, ranging from 49 to $74 \%$ of TP.

\section{Biweekly loads of TP using three different methods}

Total phosphorus loads were calculated based on fortnightly grab sampling, on flow-proportional sampling, and on modeled concentrations from the high-frequency turbidity measurements. The loads estimated with the three different sampling techniques were similar during low-discharge periods but differed during periods of high discharge (Fig. 8). During the high-discharge periods, TP loads calculated from flow-proportional concentrations were 19-51\% larger than the modeled loads and 34-70\% larger than the loads determined from grab sampling (95th prediction intervals). On a total basis for the whole study period, TP load in the agricultural monitoring catchment U8 calculated with flow-proportional sampling, highfrequency measurements, and grab sampling was $282 \mathrm{~kg}$, $178 \mathrm{~kg}$, and $123 \mathrm{~kg}$, respectively.

Three different estimates of the TP load in the case catchment were obtained and compared. The relatively low loads from the grab sampling can be explained by the fact that the sampling missed two of the high-flow episodes, by sampling approximately 5 days before or after

Table 4 Concentrations of suspended solids (SS), total phosphorus (TP), and particulate phosphorus (PP) from fortnightly grab sampling

\begin{tabular}{|c|c|c|c|c|c|c|}
\hline & \multirow{2}{*}{$\begin{array}{l}\text { Turbidity } \\
\text { (FNU) } \\
\text { Sensor, in situ }\end{array}$} & \multicolumn{2}{|l|}{$\mathrm{SS}\left(\mathrm{mg} \mathrm{L}^{-1}\right)$} & \multicolumn{2}{|l|}{$\mathrm{TP}\left(\mathrm{mg} \mathrm{L}^{-1}\right)$} & \multirow{2}{*}{$\begin{array}{l}\text { PP }\left(\mathrm{mg} \mathrm{L}^{-1}\right) \\
\text { Fortnightly grab } \\
\text { sampling }\end{array}$} \\
\hline & & $\begin{array}{l}\text { Fortnightly grab } \\
\text { sampling }\end{array}$ & $\begin{array}{l}\text { Turbidity-based } \\
\text { SS }\end{array}$ & $\begin{array}{l}\text { Fortnightly grab } \\
\text { sampling }\end{array}$ & $\begin{array}{l}\text { Turbidity-based } \\
\text { TP }\end{array}$ & \\
\hline$N$ & 147 & 11 & 147 & 11 & 147 & 11 \\
\hline Mean & 119.8 & 89 & 97 & 0.17 & 147 & 0.12 \\
\hline Min. & 15.5 & 0 & 18 & 0.061 & 0.07 & 0.03 \\
\hline Median & 46.2 & 54 & 48 & 0.13 & 0.13 & 0.092 \\
\hline $\begin{array}{l}\text { 75th } \\
\text { percentile }\end{array}$ & 106.6 & 138 & 101 & 0.30 & 0.21 & 0.21 \\
\hline $\begin{array}{l}\text { 90th } \\
\text { percentile }\end{array}$ & 389.1 & 314 & 320 & 0.40 & 0.42 & 0.31 \\
\hline Max. & 902.7 & 336 & 677 & 0.42 & 0.67 & 0.34 \\
\hline
\end{tabular}

Daily turbidity values from high-frequency measurements and concentrations of SS and TP were modeled based on high-frequency turbidity. Measurements in the agricultural monitoring catchment U8 in the period 4 July-3 December 2012 are shown 


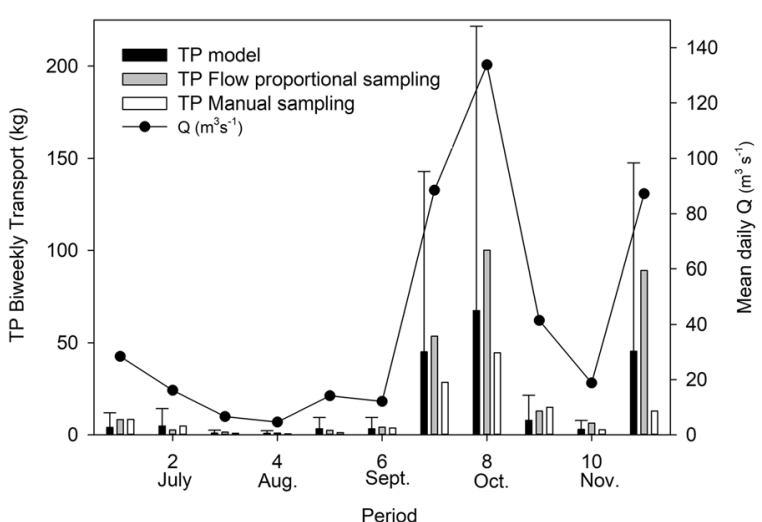

Fig. 8 Fortnightly total phosphorus (TP) transport in the agricultural monitoring catchment U8 in the period 4 July-3 December 2012. Transport was calculated from grab sampling, flowproportional concentration, and high-frequency turbidity measurements at the catchment outlet. The error bars in the modeled transport represent the 95 th prediction interval. The line connecting dots indicates mean daily discharge

the discharge peak. Underestimation of TP load in fortnightly grab sampling is consistent with other findings for clay-dominated catchments in Sweden (Kyllmar et al. 2014a). This shows that it is essential to complement grab fortnightly sampling with other sampling techniques (e.g., flow-proportional sampling) to obtain more representative annual load estimates.

The discrepancy between the loads from flowproportional sampling and high-frequency measurements (e.g., turbidity measured by sensor) is not as straightforward to explain. The relationship between TP and turbidity was linear for all the grab sampling data, where the value of the latter ranged up to $503 \mathrm{FNU}$, but in the highfrequency measurements, it ranged up to $1000 \mathrm{FNU}$. If the relationship between TP and turbidity levels off at higher values, that would lead to underestimation of the load from turbidity measurements at higher values of turbidity. The study did not include the period between January and June because the equipment was unable to measure during winter due to freezing. During these months, and especially during March and April, large flow events usually take place in the catchment due to melting snow. In future studies, it is important to cover these large events to include higher turbidity values in the load estimations. It is also possible that real TP values are even higher than those obtained by flow-proportional sampling. When the Swedish flow-proportional method was applied to high-frequency in situ data on TP for three streams in Ireland, it was concluded that the median estimated load was $80-96 \%$ of that based on in situ analysis (Cassidy et al. 2018). Another possible explanation for the discrepancies between the load estimates in the present study was that the different types of sampling (i.e., suction pipe, sensor, and grab sampling) took place at different locations in the stream, which could lead to errors due to the vertical and horizontal heterogeneity of SS (Horowitz 2013). Horowitz et al. (1990) observed that the type of sampler and the location and depth of sampling in a stream cross section affect SS and associated trace element concentrations and, consequently, load calculations. Suspended solids are composed of particles of different sizes and densities, and thus their distribution in the stream cross section is not necessarily homogeneous, which could lead to misrepresentation of P if, e.g., only small-sized and more P-enriched particles are sampled. Large rivers are more sensitive to variations in suspended solids in their cross section (Horowitz et al. 1990; Bouchez et al. 2010; Guinoiseau et al. 2016), but this issue might also be important in small streams such as that used in our case study.

Baseflow index in the catchment was low (0.3) which shows that the catchment behavior is flashy, with a rapid response to intense rainfall. There is a high proportion of clay soils in the catchment, and therefore, the contribution of the groundwater sources is low. Johnes (2007) observed that, when sampling infrequently, the uncertainty in the load estimations is higher for systems with a significant quickflow hydrological response than for systems with a higher baseflow index. In order to reduce uncertainty in the load estimates, more samples would be needed, especially at high values of turbidity (Fig. 8). The number of grab samples used in the present study was low (11), and therefore, more samples need to be used in future studies. Sensor measurements need to be complemented with manual sampling to calibrate/recalibrate the turbidity-TP relationship. Taking a grab sample during peak concentrations is a challenge due to the short duration of peak events, often just a few hours, but is very important in order to establish an accurate relationship between turbidity and TP. This can be solved by using telemetry-based infrastructure for continuous recording and transmission of flow data. This would provide access to data at any time; e.g., an alert could be sent when a high-flow event is occurring.

\section{Conclusions}

Turbidity was found to be a good predictor of SS and TP, with a general relationship for most stream types. However, the error related to predicting SS and TP from 
turbidity for all the data was larger than that for the sitespecific regressions in $75 \%$ and $90 \%$ of the cases, respectively. For single sites, there was a large range in how well turbidity could predict SS and TP $\left(r^{2}\right.$ ranged from 0.27 to 0.98 and from 0.10 to 0.94 , respectively). Thus, a specific relationship based on grab samples should be established before a decision on deploying a sensor at a site is taken. There was a good relationship between SS and turbidity for catchments with a larger percentage of agricultural land. The relationship between TP and turbidity was stronger for catchments with high TP concentrations. These catchments in Sweden often have a high proportion of agricultural land, which is valuable, considering that most $\mathrm{P}$ export occurs from agricultural areas and appropriate mitigation measurements need to be focused there.

The case study showed that fortnightly grab sampling runs the risk of underestimating sediment and nutrient loads, as it fails to capture the highly temporal dynamics of these constituents. During the study period, fortnightly grab sampling only captured half of the high flow peaks. Flow-proportional sampling better captures SS and $\mathrm{P}$ loads but does not provide information on the short-term variations in concentrations needed for process evaluation. The TP loads estimated from grab sampling and modeled values were $34-70 \%$ and $19-51 \%$ smaller, respectively, than the loads from flowproportional concentrations. To improve estimations of TP loads, more samples at high turbidity values should be taken. Turbidity should also be measured during a longer period in order to capture most of the large flow peaks. In the present case, for instance, large flow snowmelt peaks were not covered.

High-frequency measurements of turbidity by sensors in streams have great potential to increase knowledge about the sources and dynamics of SS and TP in streams. They can capture changes in concentrations not detected by flow-proportional sampling and provide more accurate estimates of TP loads than grab sampling. In addition, they offer the possibility to study withinchannel processes and observe changes in water quality as a result of nutrient mitigation efforts over time. More accurate assessment of $\mathrm{P}$ loads derived from sensor data can also improve the calibration of models used to calculate the rates, retention, and source apportionment of $\mathrm{P}$ in river basins. Prior to establishing sensor measurements as a monitoring strategy, the variation in SS and TP in stream cross sections needs to be studied, to avoid misrepresentation of these constituents. In addition, to obtain a reliable relationship, intense sampling covering the whole flood hydrograph is needed. Climate change is expected to increase water flow and increase the incidence of strong high flows, increasing losses of SS and P. High-frequency measurements of turbidity as a surrogate for SS and $\mathrm{P}$ would provide valuable information for future projections and for quantifying the uncertainty in those projections.

Acknowledgments The water chemistry data used in this study originated from different monitoring programs funded by the Swedish Environmental Protection Agency, Swedish Agency for Marine and Aquatic Management, Swedish Board of Agriculture, county administration boards, and regional water boards. The data were made available for public use by the national data host Miljödata MVM (https://miljodata.slu.se/mvm/) and by the data host Jordbruksvatten at the Swedish University of Agricultural Sciences (http://jordbruksvatten.slu.se/). By doing so, they have enabled the use of the data far beyond the original aim of the monitoring programs, as demonstrated by this study. A special thanks to Emil Back who helped with catchment delineation and extraction of land use data. We would also like to thank the two anonymous reviewers for their valuable comments that improved the manuscript.

Funding Information Open access funding provided by Swedish University of Agricultural Sciences.

Open Access This article is distributed under the terms of the Creative Commons Attribution 4.0 International License (http:// creativecommons.org/licenses/by/4.0/), which permits unrestricted use, distribution, and reproduction in any medium, provided you give appropriate credit to the original author(s) and the source, provide a link to the Creative Commons license, and indicate if changes were made.

\section{References}

Bechmann, M., \& Øgaard, A. F. (2013). Water quality changes following intensive focus on mitigation methods to reduce phosphorus losses in the catchment of lake Western Vansjø, Norway. Proceedings of International Conference on Realistic Expectations for Improving European Waters, Budapest, Hungary.

Bieroza, M., Heathwaite, A. L., Bechmann, M., Kyllmar, K., \& Jordan, P. (2018). The concentration-discharge slope as a tool for water quality management. Science of the Total Environment, 630, 738-749. https://doi.org/10.1016/j. scitotenv.2018.02.256.

Bilotta, G. S., \& Brazier, R. E. (2008). Understanding the influence of suspended solids on water quality and aquatic biota. Water Research, 42, 2849-2861.

Bishop, K., Buffam, I., Erlandsson, M., Folster, J., Laudon, H., Seibert, J., et al. (2008). Aqua incognita: the unknown headwaters. Hydrological Processes, 22, 1239-1242. https://doi. org/10.1002/hyp.7049. 
Bouchez, J., Lajeunesse, E., Gaillardet, J., France-Lanord, C., Dutra-Maia, P., \& Maurice, L. (2010). Turbulent mixing in the Amazon River: the isotopic memory of confluences. Earth and Planetary Science Letters, 290, 37-43. https://doi.org/10.1016/j.epsl.2009.11.054.

Bowes, M. J., House, W. A., \& Hodgkinson, R. A. (2003). Phosphorus dynamics along a river continuum. Science of the Total Environment, 313, 199-212. https://doi. org/10.1016/S0048-9697(03)00260-2.

Bowes, M. J., Smith, J. T., \& Neal, C. (2009). The value of highresolution nutrient monitoring: a case study of the River Frome, Dorset, UK. Journal of Hydrology, 378, 82-96. https://doi.org/10.1016/j.jhydrol.2009.09.015.

Brauer, N., O'Geen, A. T., \& Dahlgren, R. A. (2009). Temporal variability in water quality of agricultural tailwaters: implications for water quality monitoring. Agricultural Water Management, 96, 1001-1009. https://doi.org/10.1016/j. agwat.2009.01.011.

Bright, C. E., Mager, S. M., \& Horton, S. L. (2018). Predicting suspended sediment concentration from nephelometric turbidity in organic-rich waters. River Research and Applications, 34, 640-648.

Cassidy, R., \& Jordan, P. (2011). Limitations of instantaneous water quality sampling in surface-water catchments: comparison with near-continuous phosphorus time-series data. Journal of Hydrology, 405, 182-193. https://doi. org/10.1016/j.jhydrol.2011.05.020.

Cassidy, R., Jordan, P., Bechmann, M., Kronvang, B., Kyllmar, K., \& Shore, M. (2018). Assessments of composite and discrete sampling approaches for water quality monitoring. Water Resources Management, 32, 3103-3118. https://doi. org/10.1007/s11269-018-1978-5.

Davies-Colley, R. J., \& Smith, D. G. (2001). Turbidity, suspended sediment, and water clarity: a review. Journal of the American Water Resources Association, 37, 1085-1101. https://doi.org/10.1111/j.1752-1688.2001.tb03624.x.

Davies-Colley, R. J., Ballantine, D. J., Elliott, S. H., Swales, A., Hughes, A. O., \& Gall, M. P. (2014). Light attenuation-a more effective basis for the management of fine suspended sediment than mass concentration? Water Science and Technology, 69, 1867-1874. https://doi.org/10.2166 /wst.2014.096.

Duvert, C., Gratiot, N., Némery, J., Burgos, A., \& Navratil, O. (2011). Sub-daily variability of suspended sediment fluxes in small mountainous catchments \&ndash implications for community-based river monitoring. Hydrology and Earth System Sciences, 15, 703-713. https://doi.org/10.5194/hess15-703-2011.

European Commission. (1993). CORINE Land Cover map and technical guide. European Union Directorate-General Environment (Nuclear Safety and Civil Protection), Luxembourg.

Ferreira, J. G., Vale, C., Soares, C. V., Salas, F., Stacey, P. E., Bricker, S. B., Silva, M. C., \& Marques, J. C. (2007). Monitoring of coastal and transitional waters under the E.U. Water Framework Directive. Environmental Monitoring and Assessment, 135, 195-216. https://doi.org/10.1007/s10661007-9643-0.

Gippel, C. J. (1995). Potential of turbidity monitoring for measuring the transport of suspended solids in streams. Hydrological Processes, 9(1), 83-97.
Grayson, R., Finlayson, B. L., Gippel, C., \& Hart, B. (1996). The potential of field turbidity measurements for the computation of total phosphorus and suspended solids loads. Journal of Environmental Management, 47(3), 257-267.

Guinoiseau, D., Bouchez, J., Gélabert, A., Louvat, P., Filizola, N., \& Benedetti, M. F. (2016). The geochemical filter of large river confluences. Chemical Geology, 441, 191-203. https://doi.org/10.1016/j.chemgeo.2016.08.009.

Gustard, A., Bullock, A., \& Dixon, J. M.. (1992). Low flow estimation in the United Kingdom. Wallingford, Institute of Hydrology, 88pp. (IH Report No. 108).

Hach. (2009). DOC023.54.03232 SOLITAX sc: User Manual. Retrieved from https://www.hach.com/asset-get.downloaden.jsa?id=7639982980. Accessed 3 Mar 2017.

Hart, R. (2003). Dynamic pollution control - time lags and optimal restoration of marine ecosystems. Ecological Economics, 47, 79-93. https://doi.org/10.1016/j. ecolecon.2002.09.002.

Hayes, J. C., Godbold, E. E., \& Barfield, B. J. (2001). Turbidity based on sediment characteristics for southeastern US soils. Soil Erosion Research for the 21st Century, Proceedings.

HELCOM. (2013). HELCOM Copenhagen Ministerial Declaration 2013 Copenhagen, Denmark.

HELCOM. (2015). HELCOM Guidelines for the annual and periodical compilation and reporting of waterborne pollution inputs to the Baltic Sea (PLC-Water).

Heppell, C. M., \& Chapman, A. S. (2006). Analysis of a twocomponent hydrograph separation model to predict herbicide runoff in drained soils. Agricultural Water Management, 79(2), 177-207.

Horowitz, A. J. (2008). Determining annual suspended sediment and sediment-associated trace element and nutrient fluxes. Science of the Total Environment, 400, 315-343. https://doi. org/10.1016/j.scitotenv.2008.04.022.

Horowitz, A. J. (2013). A review of selected inorganic surface water quality-monitoring practices: are we really measuring what we think, and if so, are we doing it right? Environmental Science \& Technology, 47, 2471-2486. https://doi. org/10.1021/es304058q.

Horowitz, A. J., Rinella, F. A., Lamothe, P., Miller, T. L., Edwards, T. K., Roche, R. L., \& Rickert, D. A. (1990). Variations in suspended sediment and associated trace-element concentrations in selected riverine cross-sections. Environmental Science \& Technology, 24, 1313-1320. https://doi. org/10.1021/es00079a003.

Horsburgh, J. S., Jones, A. S., Stevens, D. K., Tarboton, D. G., \& Mesner, N. O. (2010). A sensor network for high frequency estimation of water quality constituent fluxes using surrogates. Environmental Modelling \& Software, 25, 1031-1044.

Johnes, P. J. (2007). Uncertainties in annual riverine phosphorus load estimation: impact of load estimation methodology, sampling frequency, baseflow index and catchment population density. Journal of Hydrology, 332, 241, 258. https://doi. org/10.1016/j.jhydrol.2006.07.006.

Jones, A. S., Stevens, D. K., Horsburgh, J. S., \& Mesner, N. O. (2011). Surrogate measures for providing high frequency estimates of total suspended solids and total phosphorus concentrations. Journal of the American Water Resources Association, 47, 239-253. https://doi.org/10.1111/j.17521688.2010.00505.x. 
Jones, A. S., Horsburgh, J. S., Mesner, N. O., Ryel, R. J., \& Stevens, D. K. (2012). Influence of sampling frequency on estimation of annual total phosphorus and total suspended solids loads. Journal of the American Water Resources Association, 48, 1258-1275.

Jordan, P., Arnscheidt, A., McGrogan, H., \& McCormick, S. (2007). Characterising phosphorus transfers in rural catchments using a continuous bank-side analyser. Hydrology and Earth System Sciences, 11, 372-381.

Karlson, K., Rosenberg, R., \& Bonsdorff, E. (2002). Temporal and spatial large-scale effects of eutrophication and oxygen deficiency on benthic fauna in Scandinavian and Baltic watersa review. In R. N. Gibson, M. Barnes, \& R. J. A. Atkinson (Eds.), Oceanography and marine biology (Vol. 40, pp. 427489). London: Taylor \& Francis Ltd.

Kyllmar, K., Bechmann, M., Deelstra, J., Iital, A., BlicherMathiesen, G., Jansons, V., et al. (2014a). Long-term monitoring of nutrient losses from agricultural catchments in the Nordic-Baltic region - a discussion of methods, uncertainties and future needs. Agriculture, Ecosystems \& Environment. https://doi.org/10.1016/j.agee.2014.07.005.

Kyllmar, K., Forsberg, L. S., Andersson, S., \& Mårtensson, K. (2014b). Small agricultural monitoring catchments in Sweden representing environmental impact. Agriculture Ecosystems \& Environment, 198, 25-35. https://doi. org/10.1016/j.agee.2014.05.016.

Lacour, C., Joannis, C., \& Chebbo, G. (2009). Assessment of annual pollutant loads in combined sewers from continuous turbidity measurements: sensitivity to calibration data. Water Research, 43, 2179-2190.

Lange, J., \& Haensler, A. (2012). Runoff generation following a prolonged dry period. Journal of Hydrology, 464-465, 157164.

Löfgren, S., Ring, E., von Bromssen, C., Sorensen, R., \& Hogbom, L. (2009). Short-term effects of clear-cutting on the water chemistry of two boreal streams in northern Sweden: a paired catchment study. Ambio, 38(7), 347-356.

Minella, J. P. G., Merten, G. H., Reichert, J. M., \& Clarke, R. T. (2008). Estimating suspended sediment concentrations from turbidity measurements and the calibration problem. Hydrological Processes, 22, 1819-1830. https://doi. org/10.1002/hyp.6763.

OSPAR Commission. (2014). Riverine Inputs and Direct Discharges monitoring programme (RID). HASEC 14/14/1, Annex 8.

Pellerin, B. A., Wollheim, W. M., Feng, X. H., \& Vorosmarty, C. J. (2008). The application of electrical conductivity as a tracer for hydrograph separation in urban catchments. Hydrological Processes, 22(12), 1810-1818.

Pfannkuche, J., \& Schmidt, A. (2003). Determination of suspended particulate matter concentration from turbidity measurements: particle size effects and calibration procedures. Hydrological Processes, 17, 1951-1963.

Rode, M., Wade, A. J., Cohen, M. J., Hensley, R. T., Bowes, M. J., Kirchner, J. W., Arhonditsis, G. B., Jordan, P., Kronvang, B., Halliday, S. J., Skeffington, R. A., Rozemeijer, J. C., Aubert, A. H., Rinke, K., \& Jomaa, S. (2016). Sensors in the stream: the high-frequency wave of the present. Environmental Science \& Technology, 50, 10297-10307.

Ruegner, H., Schwientek, M., Beckingham, B., Kuch, B., \& Grathwohl, P. (2013). Turbidity as a proxy for total suspended solids (TSS) and particle facilitated pollutant transport in catchments. Environmental Earth Sciences, 69, 373-380.

Ruzycki, E. M., Axler, R. P., Host, G. E., Henneck, J. R., \& Will, N. R. (2014). Estimating sediment and nutrient loads in four western Lake Superior streams. Journal of the American Water Resources Association, 50, 1138-1154. https://doi. org/10.1111/jawr.12175.

Schelker, J., Ohman, K., Lofgren, S., \& Laudon, H. (2014). Scaling of increased dissolved organic carbon inputs by forest clear-cutting — what arrives downstream? Journal of Hydrology, 508, 299-306.

Schilling, K. E., Kim, S.-W., \& Jones, C. S. (2017). Use of water quality surrogates to estimate total phosphorus concentrations in Iowa rivers. Journal of Hydrology: Regional Studies, 12, 111-121.

Schutz, J., Rydin, E., \& Huser, B. J. (2017). A newly developed injection method for aluminum treatment in eutrophic lakes: effects on water quality and phosphorus binding efficiency. Lake and Reservoir Management, 33, 152-162.

Settle, S., Goonetilleke, A., \& Ayoko, G. (2007). Determination of surrogate indicators for phosphorus and solids in urban stormwater: application of multivariate data analysis Techniques. Water, Air, and Soil Pollution, 182, 149-161.

Sharpley, A., Foy, B., \& Withers, P. (2000). Practical and innovative measures for the control of agricultural phosphorus losses to water: an overview. Journal of Environmental Quality, 29, 1-9.

Sharpley, A. N., Kleinman, P. J. A., Jordan, P., Bergstrom, L., \& Allen, A. L. (2009). Evaluating the success of phosphorus management from field to watershed. Journal of Environmental Quality, 38. https://doi.org/10.2134 /jeq2008.0056.

Skeffington, R. A., Halliday, S. J., Wade, A. J., Bowes, M. J., \& Loewenthal, M. (2015). Using high-frequency water quality data to assess sampling strategies for the EU Water Framework Directive. Hydrology and Earth System Sciences, 19, 2491-2504. https://doi.org/10.5194/hess-192491-2015.

Slaets, J. I. F., Schmitter, P., Hilger, T., Lamers, M., Piepho, H.-P., Tran Duc, V., et al. (2014). A turbidity-based method to continuously monitor sediment, carbon and nitrogen flows in mountainous watersheds. Journal of Hydrology. https://doi.org/10.1016/j.jhydro1.2014.03.034.

Smith, V. H. (2003). Eutrophication of freshwater and coastal marine ecosystems - a global problem. Environmental Science and Pollution Research, 10, 126-139.

Stubblefield, A. P., Reuter, J. E., Dahlgren, R. A., \& Goldman, C. R. (2007). Use of turbidometry to characterize suspended sediment and phosphorus fluxes in the Lake Tahoe basin, California, USA. Hydrological Processes, 21, 281-291.

Stutter, M., Dawson, J. J. C., Glendell, M., Napier, F., Potts, J. M., Sample, J., Vinten, A., \& Watson, H. (2017). Evaluating the use of in-situ turbidity measurements to quantify fluvial sediment and phosphorus concentrations and fluxes in agricultural streams. Science of the Total Environment, 607, 391402.

Sun, H., Cornish, P. S., \& Daniell, T. M. (2001). Turbidity-based erosion estimation in a catchment in South Australia. Journal of Hydrology, 253, 227-238. https://doi.org/10.1016/s00221694(01)00475-9. 
Swedish Environmental Protection Agency. (2008). Näringsbelastningen på Östersjön och Västerhavet 2006. Sveriges underlag till HELCOMs femte Pollution Load Compilation. Naturvårdsverket. Rapport 5815.

Swedish Environmental Protection Agency. (2009). Nutrient loads to the Swedish marine environment in 2006. Report 5995.

Villa, A., Fölster, J., \& Kyllmar, K. (2019). Stream monitoring data \& case sudy data (catchment U8) in Sweden - use of turbidity as a surrogate for suspended solids and phosphorus. HydroShare. https://doi.org/10.4211/hs.e69cdabd12114a79 ade60033c814d0db.

Viviano, G., Salerno, F., Manfredi, E. C., Polesello, S., Valsecchi, S., \& Tartari, G. (2014). Surrogate measures for providing high frequency estimates of total phosphorus concentrations in urban watersheds. Water Research, 64, 265-277. https://doi.org/10.1016/j.waters.2014.07.009.

Zabaleta, A., Martinez, M., Uriarte, J. A., \& Antiguedad, I. (2007). Factors controlling suspended sediment yield during runoff events in small headwater catchments of the Basque Country. Catena, 71, 179-190. https://doi.org/10.1016/j. catena.2006.06.007.

Publisher's note Springer Nature remains neutral with regard to jurisdictional claims in published maps and institutional affiliations. 